75 years of Agricultural University - Plovdiv

JUBILEE SCIENTIFIC INTERNATIONAL

CONFERENCE Plovdiv 26-28 November 2020
PERSPECTIVES ON AGRICULTURAL SCIENCE AND INNOVATIONS FOR SUSTAINABLE FOOD SYSTEMS

\title{
DOI: 10.22620 /agrisci.2021.30.004 \\ APPLICATION OF THE ALTSHULER'S ALGORITHM FOR DETERMINING THE OVERALL DIMENSIONS OF AN AGROROBOT
}

\author{
Georgi Stanchev, Ivan Mitkov, Georgi Komitov*, Atanas Sevov \\ Agricultural University - Plovdiv \\ *E-mail: gkomitov@abv.bg
}

\begin{abstract}
Modern robots perform a number of comprehensive tasks. In the agricultural sector, they are able to work on large areas with a wide range of crops with different agronomic requirements. They are highly maneuverable, some of them have the ability to rotate around its axis (can work in hard to reach places and small terrains). In the beginning, agricultural robots were slow, light and small. At the same time, they could not fully meet the requirements of their „employers“ due to the comprehensiveness of agricultural activity and the level of development of scientific and technological progress. The tasks of the agrorobots will only increase - from data collection, weeding, performing various agrotechnical activities to offering many functions.

The present article uses the famous TRIZ theory, developed by the Soviet inventor Henrik Altshuler. Its basic principle is the resolution of an unresolved contradiction by means of an inventive solution, if any. An unresolved inconsistency occurs if, when one parameter improvement is introduced into a system, another parameter deteriorates. These contradictions are called „technical contradictions“. The overall dimensions of an agricultural robot for growing some crops have been determined.
\end{abstract}

Key words: agrorobots, algoritm, Altshuler, technical contradictions

\section{INTRODUCTION}

Modern farms are expected to produce higher yields of higher quality at lower costs in a sustainable way that is less dependent on labor. The implementation of digital agriculture and their specific precision management is only possible through the proper use of agricultural robots. Agricultural scientists, farmers and producers also face the challenge of producing more food from less land in a sustainable way to meet the projected population growth requirements (Shamshiri, 2018).

In order to respond to these new and specific features, the designed agricultural robots must be able to perform comprehensive tasks. However, the biodiversity of agricultural crops is too great. This requires the use of nonspecific methods for determining the overall dimensions of agricultural robots. The scientific method for solving such problems contains the following three elements: discovery of new significant facts, comparison of facts and theory and development of new theories (Mitkov, 2011; Tonchev, 2014).

Commonly used creative tools for solving complex problems are reduced to brainstorming and other similar methods, relying mainly on the intuition, consent and knowledge of the individual team members. The methods are described as psychological and usually have a unique or unpredictable result. The idea is to save time for generating ideas, but considering all of them takes a serious resource of time (Jankova, 2010; Tonchev, 2015; Toncheva, 2016).

The theory of solving inventive tasks (TRIZ) is a kind of innovative roadmap, and can be considered as the most famous scientific 
75 years of Agricultural University - Plovdiv JUBILEE SCIENTIFIC INTERNATIONAL CONFERENCE Plovdiv 26-28 November 2020
PERSPECTIVES ON AGRICULTURAL SCIENCE AND INNOVATIONS FOR SUSTAINABLE FOOD SYSTEMS methodology for creative thinking (Ozkeser, 2018; Ilevrare, 2013).

This article discusses the determination of the overall dimensions of an agricultural robot through the application of TRIZ and the Altschuler method. Some of the agro-technical requirements of the agricultural crops to the cultivating machines have been selected and on their basis the models for the height and width of the agro-robot are derived.

\section{MATERIALS AND METHODS}

Based on the above, 25 of the most common crops in our country have been selected. The characteristic is that their processing requires increased human resources and therefore they are interesting in terms of automation of the processing processes. These crops are given in Table 1.

\section{RESULTS AND DISCUSSION}

The inter-row sowing distance, the interrow distance between the plants and the height of the plants were chosen as influencing factors.

\begin{tabular}{|c|c|c|c|c|}
\hline № & & $\begin{array}{l}\text { Intra-row distance } \\
\mathrm{X}_{1}, \mathrm{~m}\end{array}$ & Line spacing $X_{2}, m$ & Plant height $X_{3}, m$ \\
\hline 1 & & 0,5 & 1 & 0,4 \\
\hline 2 & & 0,2 & 0,7 & 0,6 \\
\hline & Eggplant (aubergine) & 0,4 & 0,7 & 0,8 \\
\hline 4 & Potato & 0,25 & 0,7 & 0,5 \\
\hline 5 & Carrot & 0,04 & 0,6 & 0,3 \\
\hline 6 & Parsley & 0,04 & 0,6 & 0,3 \\
\hline 7 & Celery & 0,25 & 0,55 & 0,7 \\
\hline 8 & Dill & 0,04 & 0,20 & 0,4 \\
\hline 9 & Onions & 0,15 & 0,6 & 0,5 \\
\hline 10 & Garlic & 0,1 & 0,6 & 0,5 \\
\hline 11 & Leek & 0,2 & 0,6 & 0,8 \\
\hline 12 & Cabbage head & 0,4 & 0,7 & 0,4 \\
\hline 13 & Cauliflower & 0,4 & 0,9 & 0,4 \\
\hline 14 & & 0,3 & 1 & 0,3 \\
\hline & Spinach & 0,05 & 0,6 & 0,25 \\
\hline 16 & Radish & 0,1 & 0,5 & 0,2 \\
\hline 17 & Beet salad & 0,4 & 0,7 & 0,4 \\
\hline 18 & Pumpkin & 1 & 2 & 0,4 \\
\hline 19 & Zucchini & 0,4 & 1 & 0,4 \\
\hline 20 & Green beans on the ground & 0,06 & 0,7 & 0,4 \\
\hline 21 & Broad beans & 0,06 & 0,7 & 0,8 \\
\hline 22 & Okra & 0,2 & 0,7 & 0,5 \\
\hline 23 & Peanut & 0,1 & 0,7 & 0,3 \\
\hline 24 & Watermelon & 1 & 2 & 0,3 \\
\hline 25 & Melon & 0,6 & 2 & 0,3 \\
\hline
\end{tabular}

The values for the maximum, average and minimum values of each factor are 
75 years of Agricultural University - Plovdiv JUBILEE SCIENTIFIC INTERNATIONAL CONFERENCE Plovdiv 26-28 November 2020
PERSPECTIVES ON AGRICULTURAL SCIENCE AND INNOVATIONS FOR SUSTAINABLE FOOD SYSTEMS determined with the help of the mathematical apparatus and are given in Table 2.

Table 2. Range of change of indicators

\begin{tabular}{|l|l|l|l|}
\hline & $\mathrm{X}_{1}, \mathrm{~m}$ & $\mathrm{X}_{2}, \mathrm{~m}$ & $\mathrm{X}_{3}, \mathrm{~m}$ \\
\hline $\mathrm{X}_{\text {MIN }}$ & 0,04 & 0,5 & 0,2 \\
\hline $\mathrm{X}_{\mathrm{O}}$ & 0,52 & 1,25 & 0,5 \\
\hline $\mathrm{X}_{\text {MAX }}$ & 1,00 & 2,00 & 0,8 \\
\hline
\end{tabular}

For greater versatility and more convenient post-processing of data, they are presented in coded form and presented in Table 3.

Table 3. Coded type of independent variables

\begin{tabular}{|c|c|c|c|}
\hline$№$ & $X_{1}$ & $X_{2}$ & $X_{3}$ \\
\hline 1 & $-0,04$ & $-0,33$ & $-0,33$ \\
\hline 2 & $-0,67$ & $-0,73$ & 0,33 \\
\hline 3 & $-0,25$ & $-0,73$ & 1 \\
\hline 4 & $-0,56$ & $-0,73$ & 0 \\
\hline 5 & -1 & $-0,87$ & $-0,67$ \\
\hline 6 & -1 & $-0,87$ & $-0,67$ \\
\hline 7 & $-0,56$ & $-0,93$ & 0,67 \\
\hline 8 & -1 & & $-0,33$ \\
\hline 9 & $-0,77$ & $-0,87$ & 0 \\
\hline 10 & $-0,88$ & $-0,87$ & 0 \\
\hline 11 & $-0,67$ & $-0,87$ & 1 \\
\hline 12 & $-0,25$ & $-0,73$ & $-0,33$ \\
\hline 13 & $-0,25$ & $-0,47$ & $-0,33$ \\
\hline 14 & $-0,42$ & $-0,33$ & $-0,67$ \\
\hline 15 & $-0,9$ & $-0,87$ & $-0,83$ \\
\hline 16 & $-0,88$ & -1 & -1 \\
\hline 17 & $-0,25$ & $-0,73$ & $-0,33$ \\
\hline 18 & 1 & 1 & $-0,33$ \\
\hline 19 & $-0,25$ & $-0,33$ & $-0,33$ \\
\hline 20 & $-0,88$ & $-0,73$ & $-0,33$ \\
\hline 21 & $-0,88$ & $-0,73$ & 1 \\
\hline 22 & $-0,67$ & $-0,73$ & 0 \\
\hline 23 & $-0,88$ & $-0,73$ & $-0,67$ \\
\hline 24 & 1 & 1 & $-0,67$ \\
\hline 25 & 0,17 & 1 & $-0,67$ \\
\hline
\end{tabular}

For data processing specialized software of VTU "Todor Kableshkov" is used and the theory of TRIZ by the method of Autshuler is used. The calculations were performed under the project „Contribution of VTU in the planning, analysis and optimization of simulation and real databases".

After computer processing the following results are obtained:

- For the width of the agrobot after optimization through the software you get (1):

$\mathrm{Y}_{1}\left(\mathrm{X}_{1}, \mathrm{X}_{2}, \mathrm{X}_{3}\right)=91,6269$ -

$6,40518 * \mathrm{X}_{1}+35,6304 * \mathrm{X}_{2}-2,10893 * \mathrm{X}_{3}-$ $43,3657 * \mathrm{X}_{1}{ }^{2}+57,8831 * \mathrm{X}_{1} \mathrm{X}_{2}-1,66265^{*} \mathrm{X}_{1} * \mathrm{X}_{3}-$ $47,9363 * \mathrm{X}_{2}{ }^{2}-0,244132 * \mathrm{X}_{2} * \mathrm{X}_{3}+2,95511 * \mathrm{X}_{3}{ }^{2}$

(1)

- For the height of the agricultural robot after the performed mathematical processing the following is obtained (2): $\mathrm{Y}_{2}\left(\mathrm{X}_{1}, \mathrm{X}_{2}, \mathrm{X}_{3}\right)=55,9046-$ $4,65858 * \mathrm{X}_{1}+1,58928 * \mathrm{X}_{2}+18,1810 * \mathrm{X}_{3}-$ $22,7041 * \mathrm{X}_{1}^{2}+31,9617 * \mathrm{X}_{1} * \mathrm{X}_{2}+2,54673 * \mathrm{X}_{1} * \mathrm{X}_{3}$ $-7,92031 * \mathrm{X}_{2}{ }^{2}-5,98907 * \mathrm{X}_{2} * \mathrm{X} 3+11,2047 * \mathrm{X}_{3}{ }^{2}$ (2)

The graphical interpretation of the proposed model from the robot width software is shown in Fig. 1, and for the height of the agrorobot in Fig. 2.

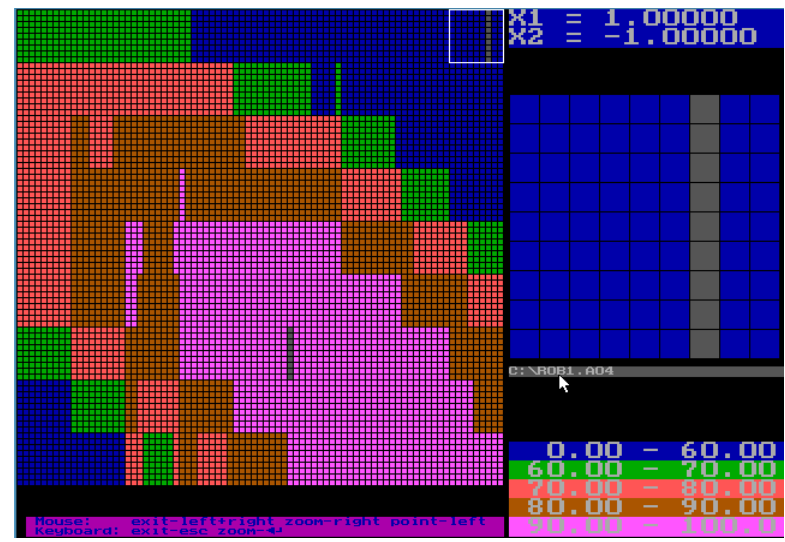

Fig. 1. The distribution of the agricultural robot width depending on the input factors

Analyzing equation (1) and Fig. 1 it is noticed that the factor $\mathrm{X}_{2}$ (the row spacing of the plants) has the greatest importance for the width of the agricultural work, but it is also complexly connected with the other two factors $X_{1}$ and $X_{2}$. Multiple correlation coefficient $\mathrm{R}=0,9906$. Fisher's check shows $F_{\text {izch }}=87,7082>F_{\text {table }}=$ 
75 years of Agricultural University - Plovdiv JUBILEE SCIENTIFIC INTERNATIONAL CONFERENCE Plovdiv 26-28 November 2020
PERSPECTIVES ON AGRICULTURAL SCIENCE AND INNOVATIONS FOR SUSTAINABLE FOOD SYSTEMS
2,5876, from which we see the adequacy of the model. The blue zones in both diagonals show a $60 \%$ hit of the results. The purple zone in the middle refers to the range of $90-100 \%$ hits. The other distribution of the ranges is shown in the lower right corner of the figure. Due to the large range of variation of the values for different crops and taking into account the above law (equation 1) and the relationships between the individual factors, as well as due to the specifics and stability of the machine, a robot width of 0.5 $\mathrm{m}$ is determined. This of course does not meet the conditions for row spacing, but this difference is compensated by changing the transverse base of the machine in the range of $0,5-1,0 \mathrm{~m}$. This change is made by telescopically increasing the transverse base of the robot (the distance between the left and right wheel of the robot). This magnification is done manually by means of fixing pins.

The analysis of the height equation (2) and Fig. 2 shows that factor $\mathrm{X}_{3}$ is the most important factor for the height of the agricultural robot. The multiple correlation coefficient is obtained $\mathrm{R}=0,9959$. Fisher's check shows $\mathrm{F}_{\mathrm{izch}}$ $=201,9819>F_{\text {table }}=2,5876$, from which we suppose that the model is adequate. The color distribution of the crop range for the individual crops is again shown in the lower right corner of the graph. The optimal height of the agricultural robot again varies by means of telescopic variation. The height of the wheel of the agricultural robot is leading, because when the width changes, it is often possible for the wheel to be under the frame of the robot. Taking into account the above considerations, the obtaining of a protected area between the plant tips and the frame, according to equation (2), the ground clearance of the machine is set at $0,5 \mathrm{~m}$. This guarantees a $0,1 \mathrm{~m}$ protected area under the robot frame.

The total height of the robot is determined by adding to equation (2) $0,3 \mathrm{~m}$ of frame height for equipment placement.

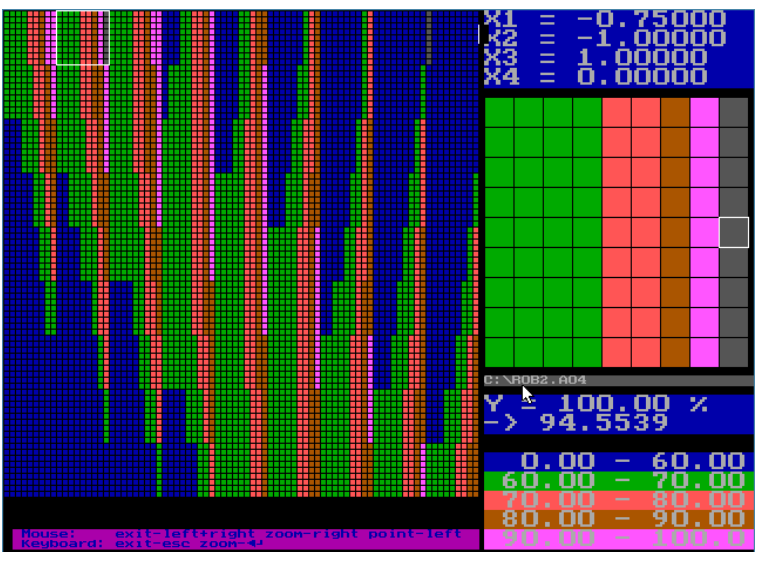

Fig. 2. The distribution of the agricultural robot height depending on the input factors

\section{CONCLUSIONS}

On the basis of TRIZ mathematical models specifications have been developed describing the width and height of an agricultural robot, depending on the agrotechnical indicators of 25 different agricultural crops. The developed models are adequate and applicable in practice.

The obtained models could be applied to optimize the parameters of agricultural robots when using crops with similar agrotechnical indicators.

\section{ACKNOWLEDGEMENT}

The authors are grateful to the Center for Research, Technology Transfer and Intellectual Property Protection at the Agricultural University - Plovdiv for the subcontract on internal project 02-20 „Power unit for agricultural robot".

The authors are grateful to the head of the project ,Contribution of VTU in the planning, analysis and optimization of simulation and real databases" from the NIP „2020“ program of VTU „,Todor Kableshkov“ Sofia, for our joint work on the project.

\section{REFERENCES}

Ilevbare I., Probert D., Phaal R., 2013. A 
75 years of Agricultural University - Plovdiv JUBILEE SCIENTIFIC INTERNATIONAL

review of TRIZ, and its benefits and challenges in practice. Technovation, vol. 33. p. 30-37.

Stimulating innovativity through TRIZ method. Nauchni trudove na RU „An. Kanchev“, vol 49, book 5.1. p. 58-62.

Mitkov, A., 2011. Teoria na eksperimenta. Dunavpress, Ruse, BG.

Ozkeser, B., 2018. An approach for sustainable innovation: TRIZ. New Trends and Issues Proceedings on Humanities and Social Sciences, vol. 5, issue 2, p. 67-73. Shamshiri R., Weltzien C., Hameed I. , Yule I., Grift T., Balasundram S., Pitonakova L., Ahmad D., Chowdhary G., 2018. Research and development in agricultural robotics: A perspective of digital farming. Int J Agric\&Biol Eng, vol. 11 No 4.

Tonchev, N., 2014. Material Science, effective solutions and Technological variants, LAMBERT Academic publishing.

Tonchev N., Ivanov M., Pencheva I., 2015. Podhod za mnogokriterialna optimizacija pri opredeljaneto na sastava i obrabotkata na splavi. XXII International scientific technical conferenceFOUNDRY 2015. Scientific technical union of mechanical $\mathrm{e}$

Tonchena A., Stoilkovski D., Tonchev N., 2016. Generalized algorithm for numerical unalysis and multicriteria optimization of multiparametric regression models. Enternational scientific journal „Industry 4.0“. Year 1, Issue 1. p. 35-42.

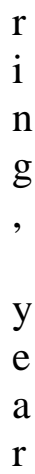

, issue 3. p. 44-47. 